\title{
Three Challenges to Central Bank Orthodoxy
}

James Bullard and Kevin L. Kliesen

Since 2007-09, the Federal Reserve has pursued a very aggressive monetary policy strategy. This strategy has been associated with healthy labor market conditions, moderate economic growth, and inflation-netting out the effects of a major oil price shock - that is close to the Federal Open Market Committee's (FOMC's) 2 percent target. Thus, with the economy returning to normal, it is natural for the FOMC to begin the process of exiting its highly accommodative policy. The FOMC has laid out several well-defined steps for this process. This strategy may be called central bank orthodoxy, since it is a natural extension of the classical view. However, three challenges to this orthodoxy have developed. Although each challenge is interesting and potentially helpful, the orthodox view provides a better basis for devising near- and medium-term monetary policy decisions. (JEL E52, E58, E63, E65)

Federal Reserve Bank of St. Louis Review, First Quarter 2016, 98(1), pp. 1-16.

$\mathbf{T}$ he current monetary policy debate in the United States is at a crossroads. Since 2007-09, the Federal Open Market Committee (FOMC) has pursued a very aggressive monetary policy strategy. This strategy has been associated with a significantly improved labor market, moderate growth, and inflation relatively close to target, net of a large oil price shock. A key question now is how to think about monetary policy going forward.

The FOMC has long suggested that the appropriate exit strategy from the highly accommodative monetary policy following the 2007-09 recession would be slow and gradual and would proceed in several well-defined steps. In the first step, the FOMC tapered and then ended its quantitative easing (QE) program during 2014. In the second step, the Committee waited for further improvement in labor markets and signaled that the policy rate would soon move off the zero lower bound, albeit in small increments that would leave substantial monetary policy accommodation in place. In the third step, still in the future, the FOMC would begin to gradually shrink the Federal Reserve's balance sheet, most likely through an end to reinvestments. ${ }^{1}$ The fourth step, well in the future, would see the balance sheet closer to precrisis levels and the policy rate more consistent with the FOMC's view of its longer-term level. ${ }^{2}$

James Bullard is president and CEO of the Federal Reserve Bank of St. Louis. Kevin L. Kliesen is a research officer and economist at the Federal Reserve Bank of St. Louis. President Bullard presented a version of this paper at the meeting of the Shadow Open Market Committee October 2 , 2015, and the annual meeting of the National Association of Business Economics (NABE) October 13, 2015. The paper was published in Business Economics (October 2015, Vol. 50, Issue 4, pp. 191-99). Copyright @ 2015, Macmillan Publishers Ltd. Reprinted with permission.

The views expressed in this article are those of the author(s) and do not necessarily reflect the views of the Federal Reserve System, the Board of Governors, or the regional Federal Reserve Banks. Articles may be reprinted, reproduced, published, distributed, displayed, and transmitted in their entirety if copyright notice, author name(s), and full citation are included. Abstracts, synopses, and other derivative works may be made only with prior written permission of the Federal Reserve Bank of St. Louis. 
The liftoff of the policy rate from near zero might be viewed by some as a momentous event, given that the FOMC has not changed this element of monetary policy since December 2008, over seven years ago. Indeed, the FOMC has not increased its intended federal funds rate target since the target was raised from 5 to 5.25 percent on June 29, 2006. Still, a liftoff of the policy rate would be a relatively minor part of the normalization story we have outlined. It is, after all, just one portion of a long-running recovery process from the events of 2007-09. Eventually, one would surely expect to see nominal interest rates at more normal levels to be consistent with a precrisis equilibrium in which inflation is at target and labor markets are functioning well.

On the eve of policy rate normalization, however, the general view outlined above was challenged from several directions. In this paper, we will provide our characterization of some of these challenges in what we hope is an easy-to-digest format.

We will describe four broad categories of thinking about current U.S. monetary policy. None of these four broad themes is strictly identified with any one individual or organization; instead, the themes represent threads of arguments one often hears in financial market commentary, academia, and policymaking circles. Of these four approaches, the first will be a "classic" interpretation of current events based on traditional ideas of successful central banking practice. This is the central bank orthodoxy referenced in the title of this paper. The other three approaches are mildly heretical. Each claims that an aspect of the orthodoxy is clearly deficient in the current policy environment. Each has some appeal, but also important drawbacks. Each departs from the classic view by arguing that "this time is different."

Our conclusion will be that each challenge to orthodoxy is interesting and potentially helpful, but ultimately has one or more drawbacks that make the orthodox view our favored basis for near- and medium-term monetary policy decisions.

We will begin by first describing our version of central bank orthodoxy. This part of the paper will be familiar to those who have followed recent speeches of Bullard (2015) on the state of monetary policy. We will then move on to the three challenges to this orthodoxy that we wish to discuss. These challenges are (i) a weakening Phillips curve relationship that can lead to arguments for a more intense focus on inflation relative to the orthodox view; (ii) very low real interest rates that can undermine the part of the orthodox view that claims monetary policy is very accommodative today; and (iii) citation of ongoing globalization as a possible reason to heed foreign economic developments distinctly and separately when making domestic monetary policy decisions. We will explain all of these challenges to orthodoxy as we proceed through these arguments.

\section{A SIMPLE DESCRIPTION OF CENTRAL BANK ORTHODOXY}

What we are calling the "classic" or "traditional" way to view current U.S. monetary policy emphasizes the cumulative success that has been achieved so far with respect to FOMC goals. The FOMC has clear objectives associated with labor market performance and inflation. Regarding inflation, the FOMC set an official target of 2 percent beginning in 2012. Concerning labor market performance, the FOMC, through its September 17, 2015, "Summary of 
Economic Projections" (SEP), has indicated that an unemployment rate of around 4.9 percent is likely to be consistent with longer-run equilibrium, as indicated in Table $1 .^{3}$

The value of the longer-run unemployment rate has drifted down recently-it was 5.6 percent within the last few years. ${ }^{4}$

Is the FOMC achieving these objectives? The classic view emphasizes that, indeed, these FOMC objectives are close to being met. As shown in Figure 1, the unemployment rate as of September 2015 was 5.1 percent and has been on a downward trend. Given the large amount of uncertainty around the concept of a long-run or natural rate of unemployment, the current 5.1 percent value is statistically indistinguishable from the FOMC's statement of the likely long-run level.

In the past two expansions, unemployment fell well into the 4 percent range; and, barring a major recessionary shock, unemployment is likely to fall to similar levels in the quarters and years ahead. This is likely regardless of the date of liftoff because monetary policy will remain exceptionally accommodative even after normalization begins. In short, the FOMC has already hit its objective on this dimension, as shown in Figure 1. In addition, labor markets are likely to continue to improve going forward, barring a major negative shock.

Many have argued that other dimensions of labor market performance should be considered in the current environment. We think this is fair, since labor markets were severely impaired in 2007-09. Indicators such as job openings and initial unemployment insurance claims look very good, while other indicators such as working part-time for economic reasons and long-term unemployment seem not as good. One way to get a handle on this issue is to consider a labor market conditions index. Such an index can be constructed by combining many different indicators of labor market performance into a single index number and then taking that index number as a better and more informed judgment of the state of the overall labor market than the unemployment rate alone. The Board of Governors of the Federal Reserve System has calculated such an index (Chung et al., 2014). As shown in Figure 2, the current level of the index is well above its average level since 1976. Labor markets might be viewed as even better than normal according to this metric.

What about the inflation side of the Federal Reserve's dual mandate? Inflation is certainly low today; in fact, it is near zero on a year-over-year basis due in part to the very large decline in oil prices beginning in 2014. In addition, recent oil price volatility suggests stabilization of oil and related commodities prices may still be some ways in the future. Although the drop in oil prices is a net positive for the U.S. economy, the sharp downward movement does inhibit year-over-year readings on headline inflation. The classic view has an answer for this-it suggests looking through large oil price shocks, either positive or negative. The reason is that energy price shocks are usually limited in their duration. Thus, relatively large increases (decreases) tend to be followed by relatively large decreases (increases). Accordingly, at this particular juncture, it may be more useful to consider the Dallas Federal Reserve's trimmed mean personal consumption expenditures (PCE) inflation measure, as seen in Figure 3. As of August 2015, this measure was running at about 1.7 percent year over year, about 30 basis points below the FOMC's target. This is low, but still reasonably close to target.

The classic view, as we are outlining it here, would then say that unemployment of 5.1 percent and underlying inflation of 1.7 percent constitute values that are exceptionally close 


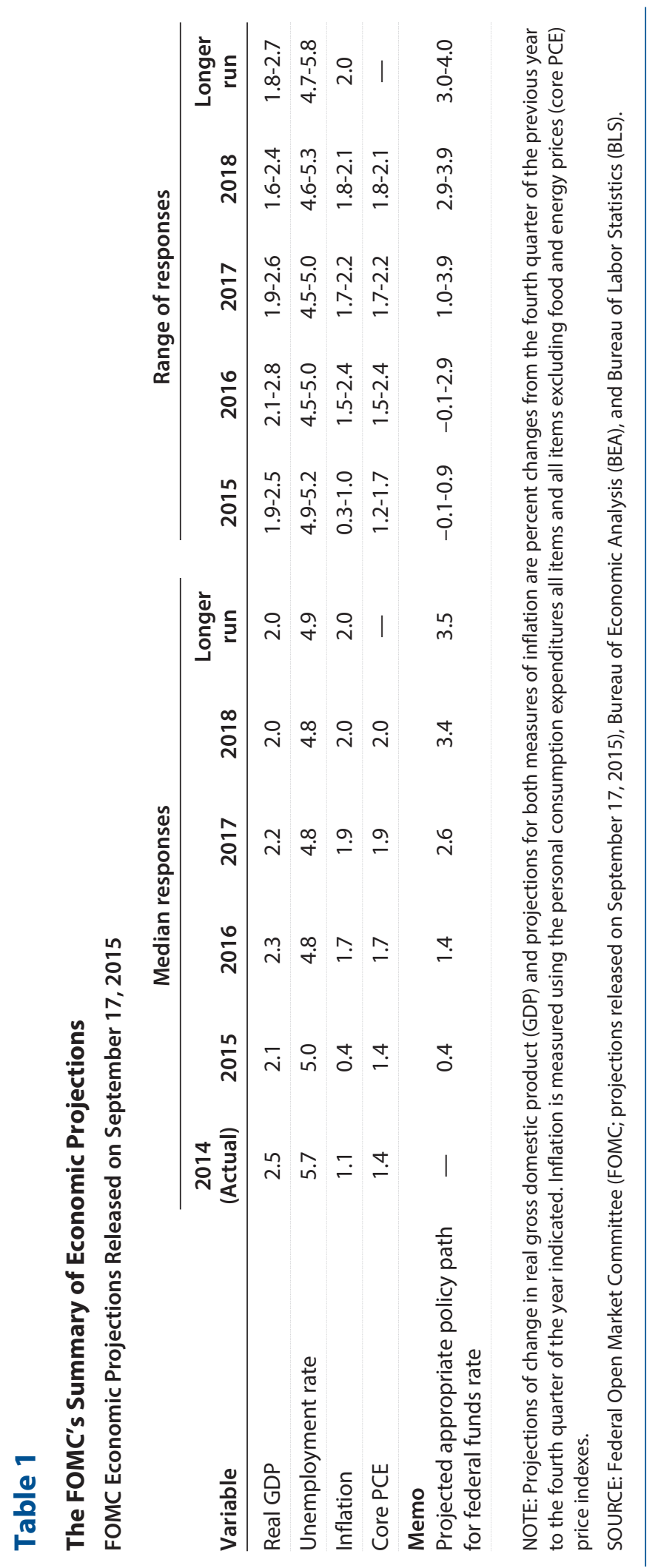




\section{Figure 1}

\section{Unemployment Rate}

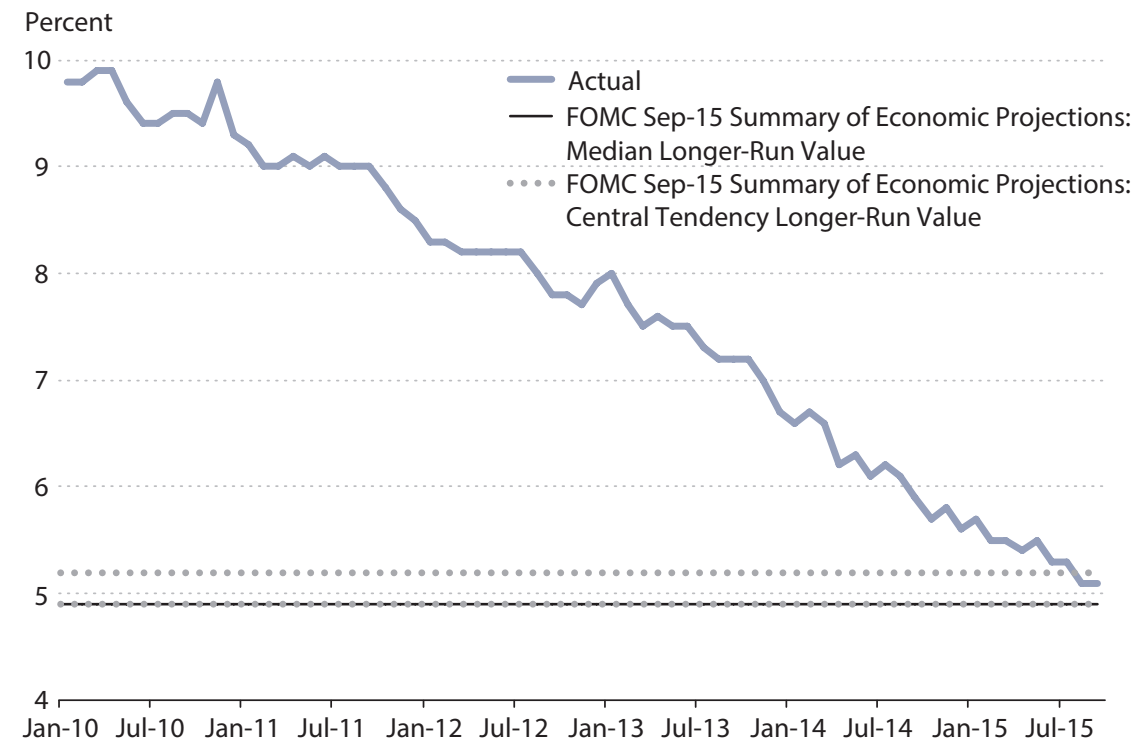

NOTE: Last observation: September 2015.

SOURCE: Bureau of Labor Statistics and Federal Reserve Board.

Figure 2

Labor Market Conditions Index

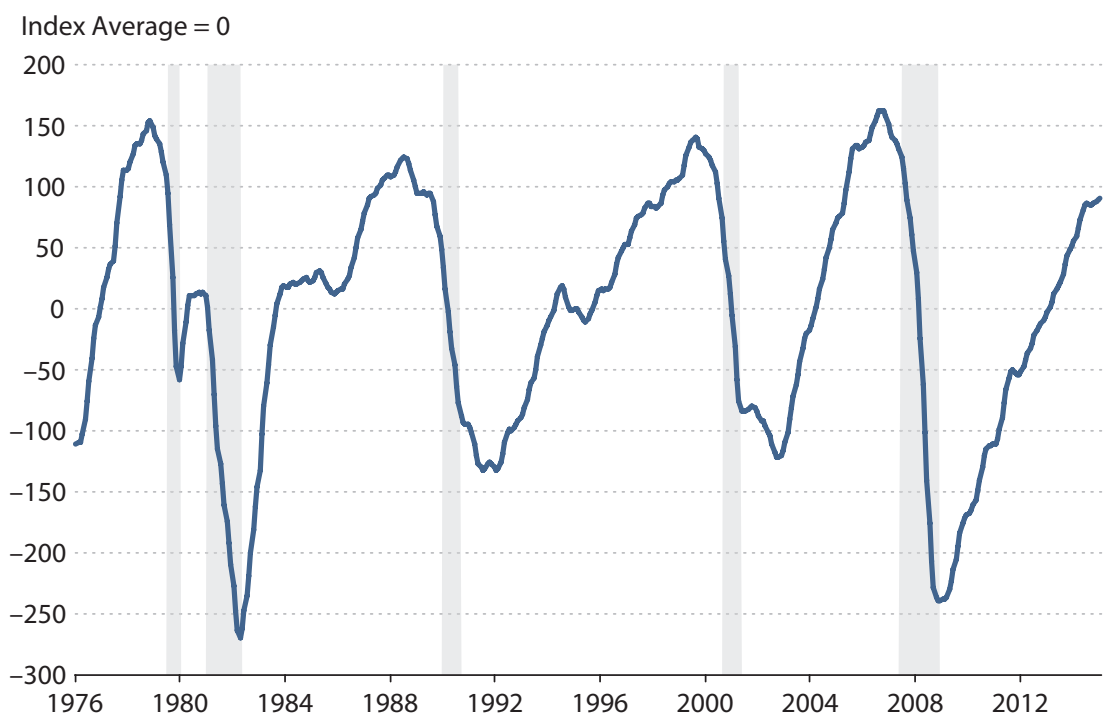

NOTE: Last observation: August 2015.

SOURCE: Federal Reserve Board and authors' calculations. 


\section{Figure 3}

\section{Inflation Rate}

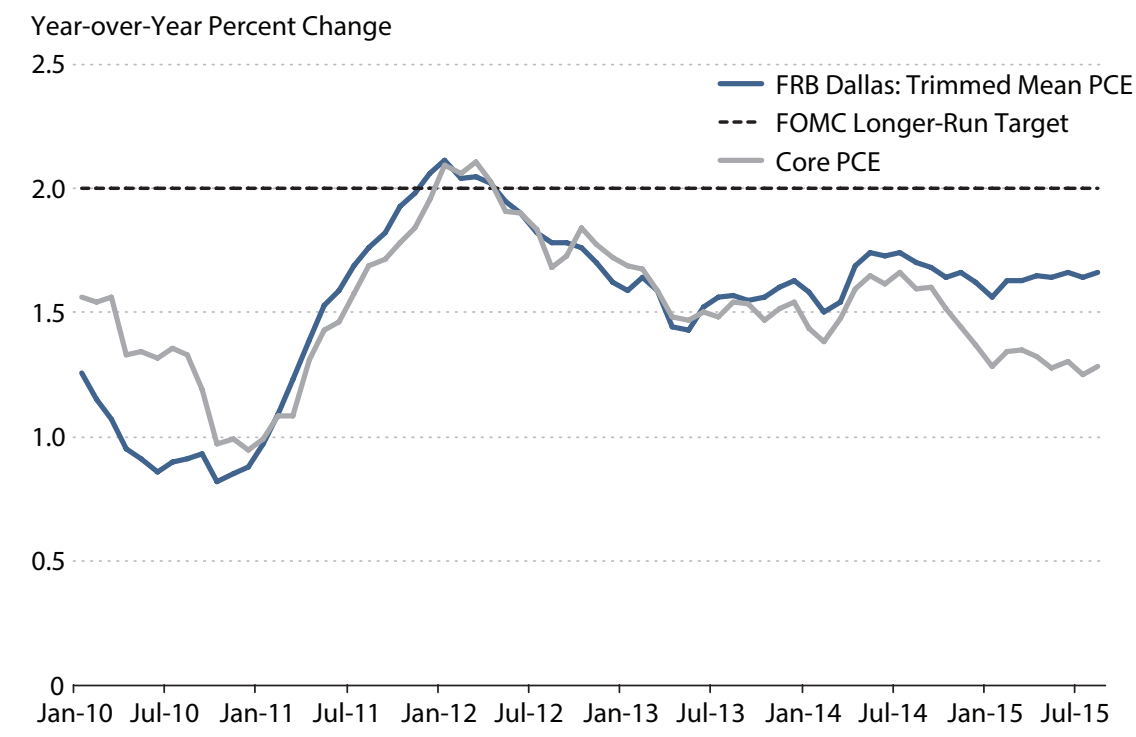

NOTE: Last observation: August 2015.

SOURCE: Bureau of Economic Analysis and the Federal Reserve Bank of Dallas.

to the objectives of the FOMC. One easy method of calculating how close the FOMC is to its dual objectives uses a quadratic function to approximate the FOMC's objective function. In effect, it measures deviations of unemployment and inflation from target:

$$
\text { Distance from goals }\left[\left(\pi_{t}-\pi^{*}\right)^{2}+\left(u_{t}-u^{*}\right)^{2}\right]^{\frac{1}{2}},
$$

where $\pi_{t}$ is the actual inflation rate at time $t ; \pi^{*}$ is the FOMC's 2 percent inflation target; $u_{t}$ is the actual unemployment rate at time $t$; and $u^{*}$ is the median longer-run value of the unemployment rate from the FOMC's September SEP (4.9 percent). ${ }^{5}$ Importantly, this version of the objective function puts equal weight on inflation and unemployment and is sometimes used to evaluate various policy options. Figure 4 shows that today's combination of labor market performance and inflation performance is about as good as it has ever been in the past 50 years or so. ${ }^{6}$

Although the metrics concerning FOMC objectives are close to normal, the policy settings are not. The FOMC has used two tools in the past seven years to conduct monetary policy. One tool has been to set the policy rate-the federal funds rate-to a near-zero value, where it remains today (see Figure 5).

Recall from Table 1 that the FOMC's SEP indicates that participants view the longer-run level of the policy rate to be about 3.5 percent. Thus, the current policy rate is more than 325 basis points lower than the long-run level. The other tool has been QE. As a result of several 


\section{Figure 4}

\section{Distance from FOMC Policy Goals}

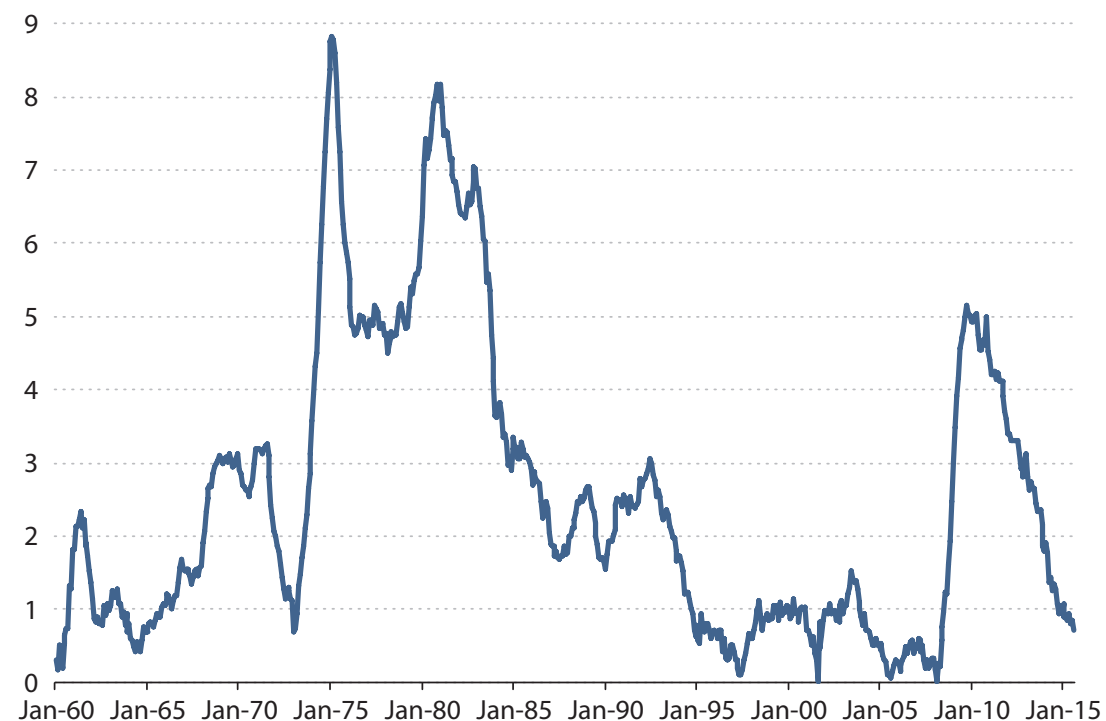

NOTE: Last observation: August 2015.

SOURCE: Bureau of Economic Analysis, Bureau of Labor Statistics, and authors' calculations.

\section{Figure 5}

\section{Federal Funds Rate}

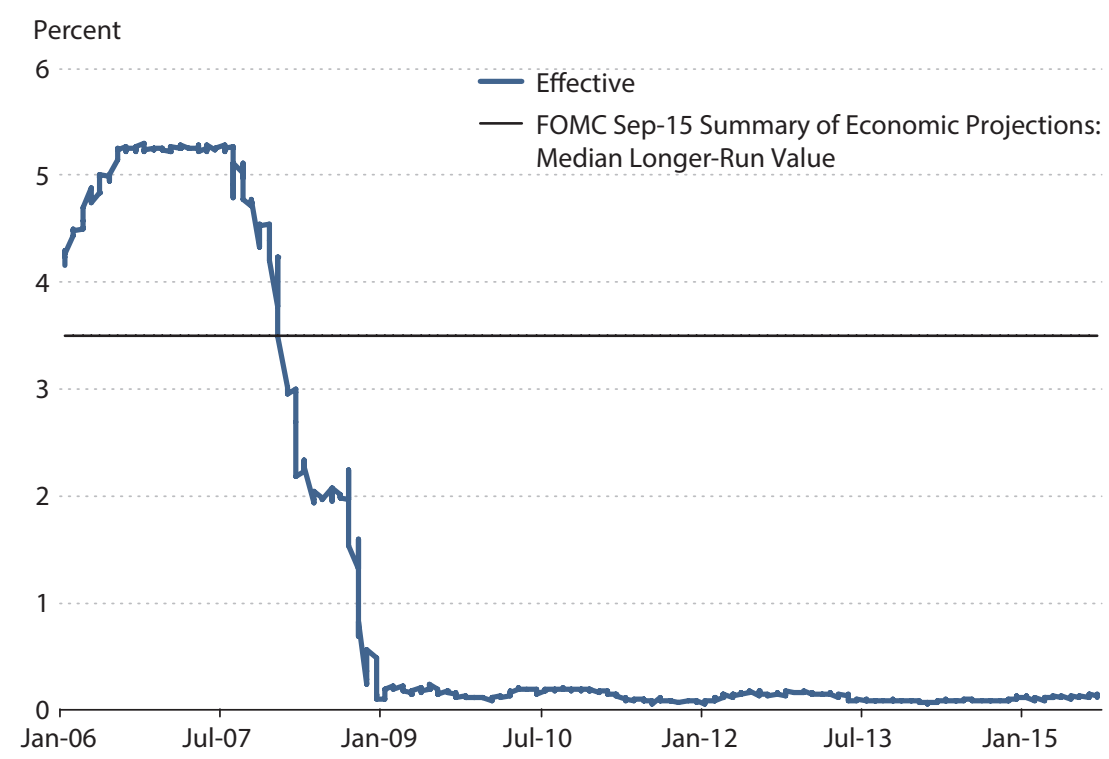

NOTE: Last observation: Week of September 30, 2015.

SOURCE: Federal Reserve Board. 


\section{Figure 6}

\section{Federal Reserve Balance Sheet}

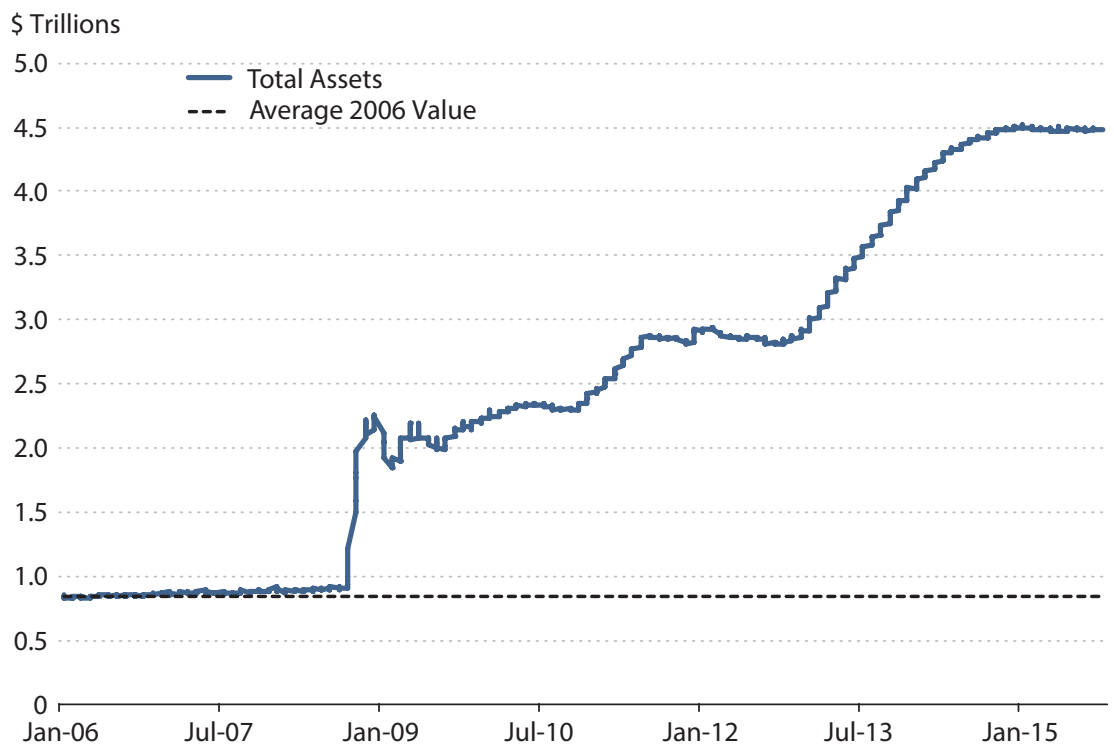

NOTE: Last observation: Week of October 7, 2015.

SOURCE: Federal Reserve Board.

rounds of QE, the Federal Reserve's balance sheet has increased from a precrisis value of about $\$ 800$ billion to about $\$ 4.5$ trillion today (see Figure 6).

These considerations-objectives met, but policy settings far from normal-suggest a policy path that will return the economy to the well understood precrisis equilibrium. Based on central bank orthodoxy, the most prudent course of action is to begin to normalize the policy rate slowly and gradually, under the interpretation that the FOMC will still be providing considerable monetary policy accommodation to the economy to guard against potential pitfalls and risks as the quarters and years ahead unfold. By adopting this prudent approach to monetary policy strategy, the FOMC may be able to lengthen the expansion longer than it may otherwise extend. However, failure to promptly begin the process of normalization runs the risk of settling into an equilibrium of unknown duration and uncertain consequences. ${ }^{7}$

We have set up this simple classic view because we think that, on balance, this view suggests the best path forward for U.S. monetary policy. But there are certainly other views with considerable merit, and we will now turn to a discussion of these alternatives. Each of the alternatives departs from an important aspect of the classic view. Again, we would hesitate to associate these alternatives with specific individuals or organizations, as most or all of us (including us at times) appeal to parts of these arguments when discussing contemporary monetary policy. 


\section{STRICT INFLATION TARGETING}

The classic view we have outlined places heavy emphasis on the attainment of FOMC goals with respect to labor market outcomes. A possible challenge to the classic view is that labor markets have been overemphasized and that it is the low inflation outcomes that are more critical today. This brings us to a second way to think about current U.S. monetary policy strategy and the first of the mildly heretical views. We will provocatively label this view "strict inflation targeting," a term often applied to Taylor-type monetary policy rules that place no weight on real variables such as output or unemployment gaps.

How could labor market outcomes be overemphasized? One version of this view is that Phillips curve relationships on which much of modern central bank practice rely have either broken down completely or are badly damaged, meaning that further expansion of the economy and tighter labor markets in the quarters and years ahead are unlikely to lead to more inflation. ${ }^{8}$

This being the case, one may wish to pursue substantially more monetary policy accommodation than otherwise-one may, for instance, keep the policy rate near zero longer.

Another version of this story is that the normal Phillips curve relationship remains intact, but the inflation rate itself contains all the information one needs to determine the extent of slack in the economy. That is, one may be able to reverse engineer the degree of slack in the economy by considering the inflation rate alone. One does not really need to know that much about the Phillips curve and its mysteries. The Phillips curve is temporarily dormant-it may or may not reassert itself in the future-and we can watch inflation for signs of life in the inflation-unemployment nexus.

Either way, whether one thinks the Phillips curve has broken down or is merely dormant, a student of the current U.S. economy taking this broad view may tend to cite inflation alone as the key indicator on which monetary policy should rely, and, hence, we label this view "strict inflation targeting." We could think of an advocate of this view as employing a Taylortype rule in which the coefficient on the unemployment gap has been set to zero.

In short, in this alternative view, policy rates should be normalized only when inflation threatens. It challenges the classic view by dispensing with or substantially discounting the empirical evidence on labor market improvement as a reason to begin policy normalization. Since we are not advocates of the Phillips curve as an organizing principle for monetary economics, the strict inflation-targeting approach has some appeal for us. Taken to its logical extreme, one could thus greatly de-emphasize current data on economic growth and labor market performance, focusing instead on inflation developments alone in considering monetary policy strategy.

Nevertheless, we do see an important drawback with this view. This type of argument might work better if the policy rate were not near zero, but instead were only mildly below its long-run level. But to use this alternative to the classic view to justify a very low policy rate near zero implies a very large elasticity between the policy rate and the inflation gap (Bullard, 2014a). One would be saying, in effect, that because a smoothed measure of inflation-such as the year-over-year Dallas Federal Reserve trimmed mean PCE-was somewhat below the inflation target (let's say 50 basis points below), the policy rate itself must be set 325 basis points 


\section{Figure 7}

\section{Taylor (1999) Rule and Strict Inflation-Targeting Rule Policy Rate Paths}

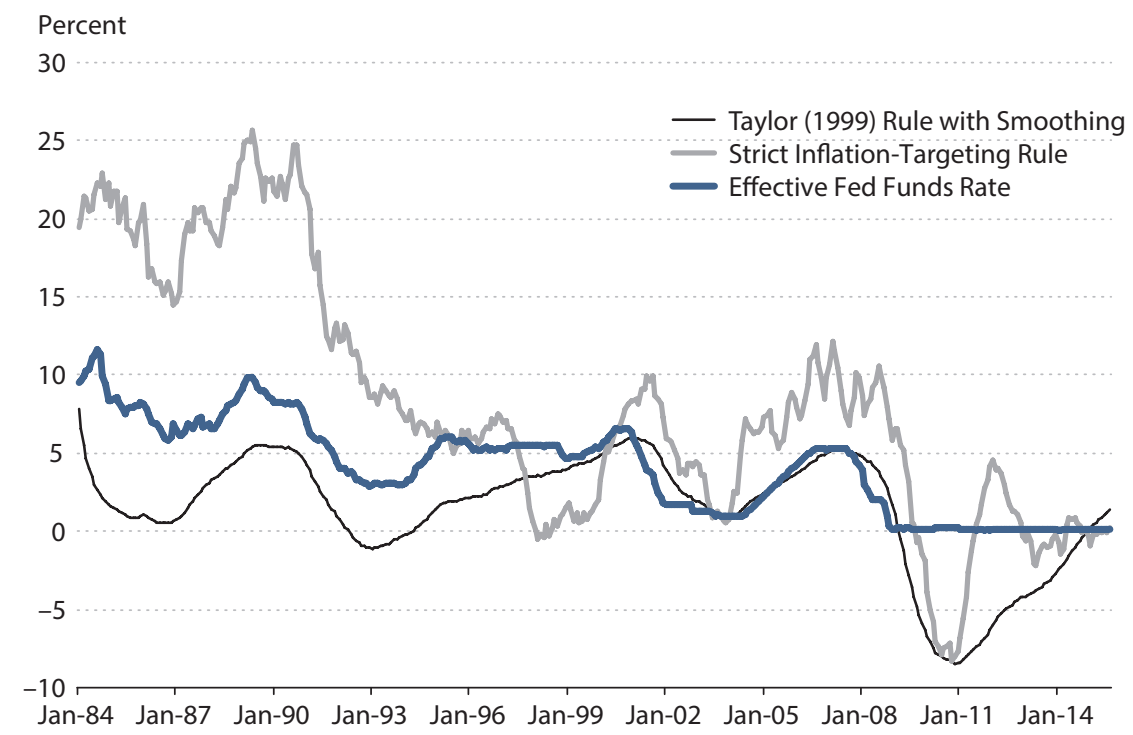

NOTE: Last observation: August 2015.

SOURCE: Federal Reserve Board, the Federal Reserve Bank of Dallas, Bureau of Labor Statistics, and authors' calculations.

below its normal value. ${ }^{9}$ The flip side would be, in the context of strict inflation targeting, that when a smoothed measure of inflation is 50 basis points above target, the appropriate policy rate would need to be set to something like 325 basis points above its normal value, on the order of a 7 percent policy rate. We can think of this strict inflation-targeting rule as engineered to justify today's near-zero policy rate based on today's inflation gap alone. This rule would produce a coefficient of 10 on the inflation gap.

Figure 7 shows what such a policy rule would have recommended since $1984 .{ }^{10}$

Such a large coefficient would have implied very high policy rates at some points in the past, including the 2000s. Given normal stochastic variation in inflation, few would have advocated this kind of policy sensitivity since it would have risked destabilizing the economy. However, that is the implication of strict inflation targeting in the current environment: a rapid adjustment of the policy rate in response to relatively benign inflation developments. In short, strict inflation targeting may provide a reason to set the policy rate below its longrun level, but not all the way to zero. For this reason, we think it may be unwise to follow this particular alternative to the classic view.

\section{LOW REAL INTEREST RATES}

The classic view as we have formulated it does not say anything about real interest rates. It implicitly assumes that policy can be conducted with a standard Taylor-type policy rule in 
which the intercept term represents a constant long-run or normal value for the policy rate. This is indeed the way Taylor-type rules were initially proposed and fit to macroeconomic data. Still, we have to be cognizant of the evidence, and current real interest rates on government debt and related instruments are exceptionally low. ${ }^{11}$ Another alternative, and mildly heretical, way to think about current U.S. monetary policy is to appeal to time-varying real interest rates and to argue that the intercept term in the Taylor-type rule is exceptionally low in the current era.

To see this, consider a generic Taylor-type monetary policy rule without too many bells and whistles. This is shown in Equation (2):

$$
I_{t}=R_{t}^{*}+\pi^{*}+1.5\left(\pi_{t}-\pi^{*}\right)+Y_{t}
$$

where $I_{t}$ is the long-run or steady-state level, which-according to the Taylor-type rulesimply says that the policy rate should be equal to its long-run or steady-state level; $R_{t}^{*}$ is the short-term real rate (which varies over time); $\pi_{t}$ is the year-over-year inflation rate; $\pi^{*}$ is the Federal Reserve's longer-run goal inflation rate (2 percent); $Y_{t}$ is the output gap and is defined as $2.3\left(u^{*}-u_{t}\right) ; u_{t}$ is the current unemployment rate; and $u^{*}$ is the long-run unemployment rate. The rule is thus stated in linear terms, with inflation gaps and output or unemployment gaps as key arguments. Let us suppose for purposes of discussion that these gaps are zeroinflation is at target and unemployment is at its long-run level - so these terms go away completely. Then it is simply the sum of the short-term real rate $\left(R_{t}^{*}\right)$ and the inflation target $\left(\pi^{*}\right)$. That is, the Taylor rule collapses to a Fisher relation, stating that the current value of the nominal policy rate is equal to the real rate plus (expected) inflation, which is equal to the inflation target at the steady state. In the orthodox view, $R^{*}$ is a constant and equal to 2 percent; so the recommended nominal policy rate is 4 percent.

The real interest rate argument is that $R_{t}^{*}$ is actually a very low value in the current macroeconomic environment. Let us suppose that the relevant short-term real interest rate is -2 percent. Then, given an inflation target of 2 percent and gaps which are zero, the recommended policy rate from a Taylor-type rule in this class would be zero. This provides an argument rationalizing today's near-zero policy rate. In other words, inflation and unemployment are near target, implying that the policy rate should also be near $R_{t}^{*}$, but $R^{*}$ is itself zero; so, everything is exactly rationalized.

What should we make of this alternative view? First, this argument as stated says that monetary policy is not accommodative right now. This is contrary to the orthodox view, which was recently expressed by Fed Chair Janet Yellen. ${ }^{12}$ Most observers of monetary policy seem to agree with Chair Yellen (via the orthodox view given earlier) that monetary policy is highly accommodative and that it will continue to be accommodative going forward. This provides one reason why the low-real-rates view is somewhat heretical. In other contexts, many might say that it is the central bank actions themselves that are driving real interest rates to very low levels.

Second, there are many competing methods for computing the real interest rate. Recall that the orthodox view is that $R^{*}$ is constant. But suppose instead that one believes that $R^{*}$ is time-varying $\left(R_{t}^{*}\right)$. In the latter case, economic theory offers several methods, but we will con- 


\section{Figure 8}

\section{Different Estimates of the Natural Real Interest Rate}

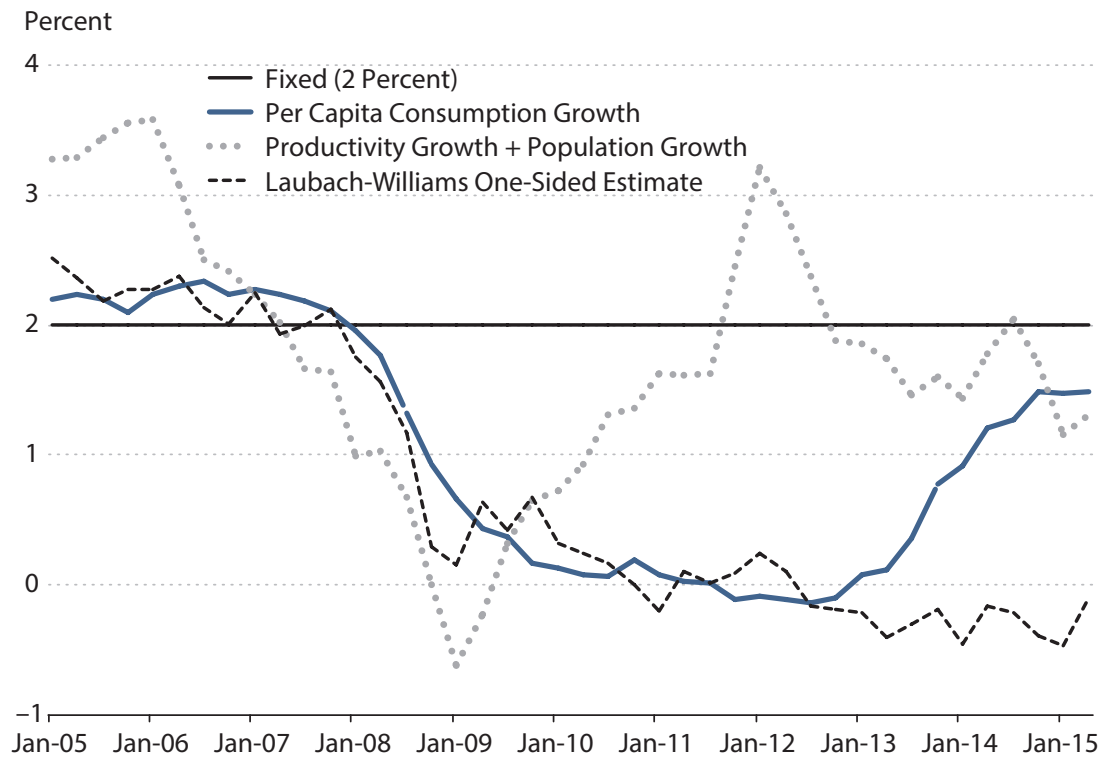

NOTE: Last observation: 2015:Q2.

SOURCE: Bureau of Economic Analysis, Bureau of Labor Statistics, Census Bureau, and authors' calculations.

sider three. One method would emphasize labor force growth and the pace of technological improvement. The pace of technological improvement is measured by total factor productivity. A second method hypothesizes that $R^{*}$ is the growth rate of per capita consumption. A third method, which many employ, is based on a statistical model. As shown in Figure 8, using these and other methods from the literature suggests that one can reasonably reach a wide variety of conclusions about the appropriate estimate of the real interest rate. ${ }^{13}$

The bottom line is that each of these three methods produces a value for $R^{*}$ greater than -2 percent. Accordingly, given the implied level of accommodation and the measurement uncertainty surrounding the estimation of the real interest rate, we think this alternative view suggests an unwise modification to the classic orthodoxy.

\section{GLOBALIZATION}

For quite a while, emerging market economies have been growing, on average, faster than developed economies. The classic view as we outlined it did not make reference to events outside U.S. borders. This may be viewed as a shortcoming in an age of globalization. The third challenge to the classic view is to suggest that, because of globalization, foreign economic developments need to be taken into account-separately and distinctly-in U.S. monetary policy deliberations. 
It may seem obvious that increasing reference to foreign economic events will be part of U.S. monetary policy going forward. But it has not been as popular as one might think, at least in portions of the international monetary policy coordination literature (Bullard and Singh, 2008; Bullard and Schaling, 2009; and Bullard, 2014b). In models, the ideas are clear. There are many countries with independent monetary policies. Each country is its own New Keynesian economy with its own shocks. Exchange rates are flexible. Monetary policymakers in each country attempt to stabilize their own economies as well as they can by reacting appropriately to the shocks in their own country through a Taylor-type monetary policy rule. A general conclusion from our reading of the literature is that in this situation, there would be little to gain from international monetary policy coordination. Roughly speaking, if policymakers in each country pursue the best domestically oriented stabilization policy available to them, the global equilibrium will be as good, or nearly as good, as the fully optimal outcome that could be attained through an appropriate coordination of monetary policy.

What does this mean in practical terms? "Domestically oriented stabilization policy" means policymaker reaction functions include only domestic variables, and these domestic variables contain all the information needed to pursue optimal policy, regardless of what is occurring in the rest of the world. Alternatively, one could imagine monetary policymakers in each country incorporating, in addition to their own output gaps and inflation gaps, foreign output gaps in their Taylor-type rules as they conduct monetary policy. The policymakers would then be adjusting their own policy rates in reaction to domestic inflation developments, domestic real developments, and-separately and distinctly-foreign real developments. The baseline result from an important class of models is that this situation does not lead to a better global equilibrium, and all countries would be just as well off focusing only on domestic inflation and domestic real developments. Why? The short answer is that it is the job of the foreign central bank to use stabilization policy in reaction to shocks in its own economy. That, in conjunction with the flexible exchange rate regime, makes it unnecessary for the domestic policymaker to react to foreign shocks.

Of course, this is just one set of models. But as a baseline, we think this provides food for thought concerning globalization and monetary policy. The models we refer to are "fully globalized" as the economies involved are simply carbon copies of one another with different shocks. Even within this environment of full globalization, the gains from international policy coordination may be small.

There is another angle on the role of foreign developments in domestic monetary policy. This is the literature on so-called global output gaps (Borio and Filardo, 2007, and Bullard, 2012). This literature argues that the output or resource gap that is most relevant for domestic inflation may actually be a global gap, which is sort of an average of output gaps across countries. In other contexts, one of us (Bullard, 2012) has explored the idea that especially for China and the United States, which are linked by a managed exchange rate regime, it may be more appropriate to think of the resource gap for the two countries jointly. Although this is interesting and we think deserving of further research attention, in truth, the measurement problems are all the more severe in attempting to calculate a global output gap as opposed to simpler domestic resource gaps. 


\section{CONCLUSION}

In this paper, we have outlined an interpretation of current events in U.S. monetary policy that we called the orthodox view. This view stresses the currently stark difference between FOMC objectives, which are arguably nearly attained, and FOMC policy tools, which remain on emergency settings. A simple and prudent approach to current policy would be to begin normalizing the policy settings in an effort to extend the length of the expansion and to avoid taking unnecessary risks associated with exceptionally low rates and a large Federal Reserve balance sheet. This would be done with the understanding that policy would remain extremely accommodative for several years. Why? Because the Federal Reserve's policy settings are far from anything that could reasonably be called restrictive. Thus, even as normalization proceeds, this accommodation would help to mitigate remaining risks to the economy during the transition.

These remarks have described what we see as three important challenges to this orthodox view. All challenges have a certain clear appeal, but also important drawbacks. All challenges contain an element of the argument that "this time is different."

The first challenge concerned possible overemphasis on labor market improvement in the orthodox view. One version would be that the empirical Phillips curve relationship is broken and, therefore, the Federal Reserve can continue a very accommodative policy without worry of pressing inflation concerns. We called this view "strict inflation targeting." A key issue with this challenge to orthodoxy is that it is difficult to use this argument to justify the exceptionally low policy rate observed in the United States today. Actually trying strict inflation targeting in the current environment would imply an exceptionally sensitive policy reaction function that might destabilize rather than stabilize the economy.

The second challenge concerned the observed low real interest rates on government debt and related instruments in the United States and globally vs. the orthodox view that real interest rates of this type move very little and only very slowly. Time-varying and low real rates can be used, via a Taylor-type rule, to rationalize the current policy rate setting of zero. An important question for this challenge to orthodoxy is whether the resulting characterization of current policy as neutral instead of accommodative is consistent with FOMC statements and financial market interpretations of current monetary policy. In addition, simple alternative measurements of an appropriate real interest rate suggest considerable uncertainty around this concept.

The final challenge deals with global concerns vs. the orthodoxy that de-emphasizes international considerations. While it may seem that, with increasing globalization, policy in one country has to take increasing account of developments in other countries, some of the literature on international monetary policy coordination in New Keynesian models suggests otherwise. In particular, at least as a baseline concept, the global equilibrium will be close to optimal if each country reacts only to domestic variables and the world is characterized by flexible exchange rates. This provides some food for thought on what globalization does and does not imply for monetary policy strategy.

In sum, while the challenges to orthodoxy presented here are certainly tangible and interesting, we do not think they provide sufficiently robust arguments to guide U.S. monetary 
policy over the near and medium term. The U.S. economy will likely enjoy better outcomes if the monetary policy orthodoxy we have described is preserved as the guiding principle. In other words, the orthodox approach can best manage the risks to the U.S. economy that arise from the dangers of maintaining policy settings in an environment where conventional gaps have narrowed to zero.

\section{NOTES}

1 At present, the FOMC reinvests the principal payments from its portfolio of agency debt and agency mortgagebacked securities. The FOMC also replaces (rolls over) maturing Treasury securities with new Treasury securities at auctions.

2 See Kliesen (2013) for a discussion of the Federal Reserve's strategy for exiting unconventional policies and the potential challenges.

3 This was the median longer-run value of the SEP (FOMC, 2015).

4 This was the mid-point of the central tendency of the January 2012 SEP (FOMC, 2012).

5 Inflation is measured as the 12-month percent change in the PCE chain-weighted price index that excludes food and energy prices (core PCE).

6 See Bullard (2015). More details can be found in Bullard (2014a).

7 See Bullard (2010) for an extended discussion of this possibility.

8 See, for instance, Blanchard, Cerutti, and Summers (2015). They find that in their Phillips curve specifications across many countries, the effect of the unemployment gap on inflation is small and often not statistically distinguishable from zero. See Owyang (2015) for a discussion of recent shifts in the U.S. Phillips curve.

9 Recall that 325 basis points is the difference between the current federal funds target rate and the FOMC's projected longer-run value of the federal funds rate from the SEP.

10 The details for the calculation of the Taylor rule with smoothing and the strict inflation-targeting rule are provided below. A version of the Taylor-type rule in Equation (2) often used in the empirical analysis of monetary policy allows for a gradual adjustment of the short-term interest rate to the target value: $I_{t}=\rho \times I_{t-1}+(1-\rho) \times\left[R^{*}+\pi^{*}+\right.$ $\left.1.5 \times\left(\pi_{t}-\pi^{*}\right)+Y_{t}\right]$, where $\pi_{t}$ denotes the Federal Reserve Bank of Dallas's year-over-year trimmed mean inflation rate, $Y_{t}=2.3 \times\left(u^{*}-u_{t}\right)$ is the output gap, and $u_{t}$ is the unemployment rate. The values of the parameters are as follows: $u^{*}=4.9$ percent, the median long-run unemployment rate from the September 2015 SEP; $\pi^{*}=2$ percent, the inflation target; $\rho=0.85$, the smoothing parameter; and $R^{*}+\pi^{*}=3.5$ percent, the long-run federal funds rate target from the September SEP. The equation for the inflation-targeting rule is $I_{t}=R^{*}+\pi^{*}+\varphi_{\pi} \times\left(\pi_{t}-\pi^{*}\right)$. With an inflation gap, $\left(\pi_{t}-\pi^{*}\right)$, of -0.3 percent, a federal funds rate gap, $I_{t}-\left(R^{*}+\pi^{*}\right)$, of -3.25 percent is rationalized by a value of $\varphi_{\pi}$ of roughly 10 . This rule implies that the nominal value of the federal funds rate $\left(I_{t}\right)$ would need to be 6.5 percent with a 0.3 percent inflation gap.

${ }^{11}$ However, real returns on capital are not (Gomme, Ravikumar, and Rupert, 2011 and 2015).

${ }^{12}$ Chair Yellen (2015) made this statement at her September 17, 2015, press conference: "The stance of monetary policy will likely remain highly accommodative for quite some time after the initial increase in the federal funds rate in order to support continued progress toward our objectives of maximum employment and 2 percent inflation."

${ }^{13}$ See Dupor (2015) for a more in-depth discussion of these alternative methods. 


\section{Bullard and Kliesen}

\section{REFERENCES}

Blanchard, O.; Cerutti, E. and Summers, L. "Inflation and Activity." Unpublished manuscript presented at the ECB Forum on Central Banking, Sintra, Portugal, May 2015.

Borio, C. and Filardo, A. "Globalisation and Inflation: New Cross-Country Evidence on the Global Determinants of Domestic Inflation." BIS Working Papers No. 227, Bank for International Settlements, May 2007.

Bullard, J. "Seven Faces of 'The Peril."' Federal Reserve Bank of St Louis Review, September/October 2010, 92(5), pp. 339-52; https://research.stlouisfed.org/publications/review/10/09/Bullard.pdf.

Bullard, J. "Global Output Gaps: Wave of the Future?" Remarks delivered at Monetary Policy in a Global Setting: China and the United States, Beijing, China, March 28, 2012; https://www.stlouisfed.org/ /media/Files/PDFs/Bullard/remarks/BullardBeijing28Mar2012Final.pdf.

Bullard, J. "Fed Goals and the Policy Stance." Remarks delivered at the Owensboro in 2065 Summit, Owensboro, KY, July 17, 2014a; https://www.stlouisfed.org/ /media/Files/PDFs/Bullard/remarks/BullardOwensboroKYChamber ofCommerce17July2014Final.pdf.

Bullard, J. "Two Views of International Monetary Policy Coordination." Remarks delivered at the 27th Asia/Pacific Business Outlook Conference, USC Marshall School of Business-CIBER, Los Angeles, CA, April 7, 2014b; https://www.stlouisfed.org/ /media/Files/PDFs/Bullard/remarks/Bullard-APBO-USC-Marshall-April-7-2014-Final.pdf.

Bullard, J. "A Long, Long Way to Go." Remarks delivered at the Community Bankers Association of Illinois Annual Meeting, Nashville, TN, September 19, 2015; https://www.stlouisfed.org/ /media/Files/PDFs/Bullard/remarks/Bullard-CBA-of-IL-Nashville-Sep-19-2015.pdf.

Bullard, J. and Schaling, E. "Monetary Policy, Determinacy, and Learnability in a Two-Block World Economy." Journal of Money, Credit and Banking, December 2009, 41(8), pp. 1585-612.

Bullard, J. and Singh, A. "Worldwide Macroeconomic Stability and Monetary Policy Rules." Journal of Monetary Economics, October 2008, 55(Supplement), pp. S34-S47.

Chung, H.; Fallick, B.; Nekarda, C. and Ratner, D. "Assessing the Change in Labor Market Conditions." Board of Governors of the Federal Reserve System FEDS Notes, May 22, 2014; http://www.federalreserve.gov/econresdata/notes/feds-notes/2014/assessing-the-change-in-labor-market-conditions-20140522.html.

Dupor, W. "Liftoff and the Natural Rate of Interest." Federal Reserve Bank of St. Louis On the Economy (blog), June 5, 2015.

Federal Open Market Committee. "Summary of Economic Projections of Federal Reserve Board Members and Federal Reserve Bank Presidents, January 2012." Board of Governors of the Federal Reserve System, January 2012.

Federal Open Market Committee. "Summary of Economic Projections of Federal Reserve Board Members and Federal Reserve Bank Presidents, September 2015." Board of Governors of the Federal Reserve System, September 2015.

Gomme, P.; Ravikumar, B. and Rupert, P. "The Return to Capital and the Business Cycle." Review of Economic Dynamics, April 2011, 14(2), pp. 262-78.

Gomme, P.; Ravikumar, B. and Rupert, P. "Secular Stagnation and Returns on Capital." Federal Reserve Bank of St. Louis Economic Synopses, 2015, No. 19; https://research.stlouisfed.org/publications/economic-synopses/ 2015/08/18/secular-stagnation-and-returns-on-capital/.

Kliesen, K. "The Fed's Strategy for Exiting from Unconventional Policy: Key Principles, Potential Challenges." Federal Reserve Bank of St. Louis The Regional Economist, October 2013, pp. 1-4; https://www.stlouisfed.org/ /media/Files/PDFs/publications/pub_assets/pdf/re/2013/d/ExitStrategy.pdf.

Owyang, M. "Has the Phillips Curve Relationship Broken Down?" Federal Reserve Bank of St. Louis On the Economy (blog), September 21, 2015;

https://www.stlouisfed.org/on-the-economy/2015/september/phillips-curve-unemployment-down-inflation-low.

Taylor, J. "A Historical Analysis of Monetary Policy Rules," in J. Taylor, ed., Monetary Policy Rules. Chicago: University of Chicago Press, 1999, pp. 319-41.

Yellen, J. "Transcript of Chair Yellen's Press Conference, September 17, 2015." Board of Governors of the Federal Reserve System, September 17, 2015. 